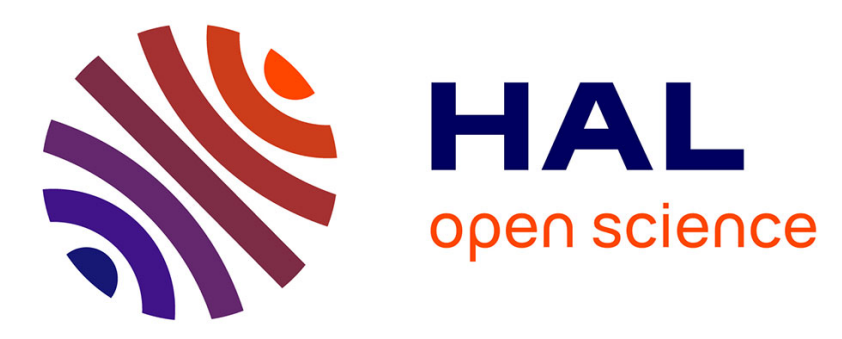

\title{
How the interplay of different control mechanisms affects the initiator efficiency factor in controlled radical polymerization: An investigation using organometallic MoIII-based catalysts
}

François Stoffelbach, Rinaldo Poli, Sébastien Maria, Philippe Richard

\section{To cite this version:}

François Stoffelbach, Rinaldo Poli, Sébastien Maria, Philippe Richard. How the interplay of different control mechanisms affects the initiator efficiency factor in controlled radical polymerization: An investigation using organometallic MoIII-based catalysts. Journal of Organometallic Chemistry, 2007, 692 (15), pp.3133-3143. 10.1016/j.jorganchem.2006.11.031 . hal-03193953

\section{HAL Id: hal-03193953 \\ https://hal.science/hal-03193953}

Submitted on 9 Apr 2021

HAL is a multi-disciplinary open access archive for the deposit and dissemination of scientific research documents, whether they are published or not. The documents may come from teaching and research institutions in France or abroad, or from public or private research centers.
L'archive ouverte pluridisciplinaire HAL, est destinée au dépôt et à la diffusion de documents scientifiques de niveau recherche, publiés ou non, émanant des établissements d'enseignement et de recherche français ou étrangers, des laboratoires publics ou privés. 
How the interplay of different control mechanisms affects the initiator

efficiency factor in controlled radical polymerization: an investigation using organometallic $\mathrm{Mo}^{\mathrm{III}}$-based catalysts

François Stoffelbach, ${ }^{\mathrm{a}}$ Rinaldo Poli, ${ }^{* a, b}$ Sébastien Maria, ${ }^{\mathrm{b}}$ and Philippe Richard ${ }^{\mathrm{a}}$

a'Laboratoire de Synthèse et d'Electrosynthèse Organométalliques, Faculté des Sciences

"Gabriel", Université de Bourgogne, 6 Boulevard Gabriel, 21000 Dijon, France

${ }^{\mathrm{b}}$ Laboratoire de Chimie de Coordination, UPR CNRS 8241 liée par convention à l'Université

Paul Sabatier et à l'Institut National Polytechnique de Toulouse, 205 Route de Narbonne,

31077 Toulouse Cedex, France.

Proofs to:

Rinaldo Poli

Tel: $+33-380396881$

Fax: $+33-380393720$

E-mail: poli@u-bourgogne.fr 


\section{Summary}

Compound $\mathrm{CpMoI}_{2}\left(i \mathrm{Pr}_{2} \mathrm{dad}\right)\left(i \mathrm{Pr}_{2} \mathrm{dad}=i \mathrm{PrN}=\mathrm{CH}-\mathrm{CH}=\mathrm{N} i \operatorname{Pr}\right)$, obtained by halide exchange from $\mathrm{CpMoCl}_{2}\left(i \mathrm{Pr}_{2} \mathrm{dad}\right)$ and $\mathrm{NaI}$, has been isolated and characterized by EPR spectroscopy, cyclic voltammetry, and X-ray crystallography. Its action as a catalyst in Atom Transfer Radical Polymerization (ATRP) and as a spin trap in Organometallic Radical Polymerization (OMRP) of styrene and methyl acrylate (MA) monomers has been investigated and compared with that of the dichloro analogue. Compound $\mathrm{CpMoCl}_{2}\left(i \mathrm{Pr}_{2} \mathrm{dad}\right)$ catalyzes the ATRP of styrene and MA with low efficiency factors $f$ (as low as 0.37 for MA and ethyl 2chloropropionate as initiator), while it irreversibly traps the corresponding growing radical chains under OMRP conditions. On the other hand, compound $\mathrm{CpMoI}_{2}\left(i \mathrm{Pr}_{2} \mathrm{dad}\right)$ has a greater ATRP catalytic activity than the dichloro analogue and yields $f=1$ for MA and ethyl 2iodopropionate as initiator. Under OMRP conditions, it does not irreversibly trap the growing radical chains. This comparison serves to illustrate the general principle that low initiator efficiency factors, sometimes observed in ATRP, may result from the interplay of the ATRP and OMRP mechanisms, when the latter ones involves an irreversible radical trapping process.

\section{Keywords}

Molybdenum, Controlled Radical Polymerization, Initiator Efficiency Factor, Atom Transfer, One-electron Oxidative Addition 


\section{Introduction}

Controlled Radical Polymerization (CRP) is rapidly becoming a widespread polymerization method because it combines the advantages of radical polymerization (functional group tolerance, non rigorous experimental conditions, adaptability to aqueous media) and living polymerization (controlled molecular weight, low polydispersities, control over the macromolecular architectures, etc.). Since its discovery in 1995 [1, 2], Atom Transfer Radical Polymerization (ATRP) has become one of the most actively investigated areas within CRP. Its key feature is the use of a spin trap consisting of a transition metal complex, which is capable to reversibly deliver a halogen atom to the reactive free radical. The latter is thereby transformed into a halogen-terminated dormant chain, while the reduced metal complex $\left(\mathrm{ML}_{\mathrm{n}}\right)$ acts as a catalyst since it is capable to reactivate the dormant chain (see Scheme 1). Systems based on a variety of transition metals, including $\operatorname{Ti}^{\mathrm{III}}[3], \mathrm{Mo}^{\mathrm{III}}[4,5]$, $\mathrm{Re}^{\mathrm{V}}[6], \mathrm{Fe}^{\mathrm{II}}[7,8], \mathrm{Ru}^{\mathrm{II}}[9], \mathrm{Ni}^{\mathrm{II}}[10], \mathrm{Ni}^{0}[11]$, and $\mathrm{Cu}^{\mathrm{I}}[12]$ have been shown effective.

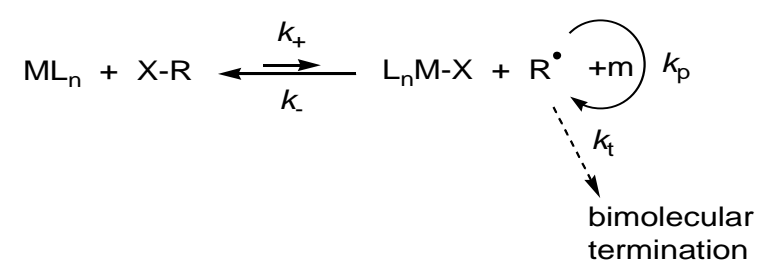

\section{Scheme 1}

Transition metal complexes have also been frequently used in a second kind of CRP, the Organometallic Radical Polymerization (OMRP) [13], which has also been commonly referred to as "Stable Free Radical Polymerization" (SFRP), a more general term also used for other mediating agents such as nitroxides and other stable free radicals. In this alternative scheme the metal complex acts as the spin trap by forming a direct metal-carbon bond (see Scheme 2). This method for controlling the active radical concentration has in fact preceded 
ATRP [14], but it is generally less popular because the metal complex remains as chain-end in the final polymer product. Unlike ATRP, OMRP has so far been highlighted only for a limited number of transition metals as radical traps (e.g. Ti ${ }^{\mathrm{III}}$ [15], Mo ${ }^{\mathrm{III}}$ [4], Os ${ }^{\mathrm{II}}$ [16], and especially $\left.\mathrm{Co}^{\mathrm{II}}[14,17-19]\right)$. An ATRP catalyst must be a complex capable to increase both its formal oxidation state and its number of valence electrons by one unit and has, in principle, the potential to act also as an OMRP spin trap. However, studies on the $\mathrm{Cu}(\mathrm{I})$-catalysed ATRP, specifically carried out to address this question, showed no evidence for the formation of $\mathrm{Cu}^{\text {II }}$-terminated dormant chains [20].

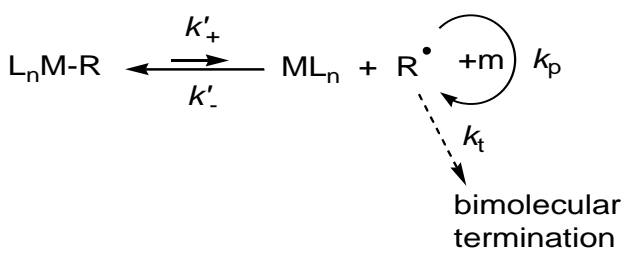

\section{Scheme 2}

In a recent study, we have shown, for the first time, the simultaneous occurrence of ATRP and OMRP controlling equilibria for the polymerization of styrene $(\mathrm{S})$ in the presence of a variety of half-sandwich $\mathrm{Mo}^{\mathrm{III}}$ complexes, $\mathrm{CpMoCl}_{2} \mathrm{~L}_{2}\left(\mathrm{~L}_{2}=\left(\mathrm{PMe}_{3}\right)_{2}\right.$, dppe, or $\left.\eta^{4}-\mathrm{C}_{4} \mathrm{H}_{6}\right)$ [4]. All these complexes are efficient spin traps for the growing polystyrene radical chain, and they also catalyse the CRP of styrene by the ATRP mechanism in the presence of (1bromoethyl)benzene (BEB) as initiator. However, whereas the polymerization has "living" characteristics when using any of the above complexes under OMRP conditions, only the phosphine complexes afford pseudo-living growth also under ATRP conditions. The butadiene complex exhibits a Catalyzed Chain Transfer (CCT) process under ATRP conditions. All these observations are summarized by the general Scheme $3(\mathrm{M}=$ $\mathrm{CpMoCl}_{2} \mathrm{~L}_{2}$ ) and have been rationalized on the basis of differences in catalyst concentration and transfer rate constant [4]. Note that the same molecule, $\mathrm{CpMoCl}_{2} \mathrm{~L}_{2}$, exerts three different 
functions: it is a catalyst for both the ATRP and the chain transfer, and a spin trap for the OMRP.

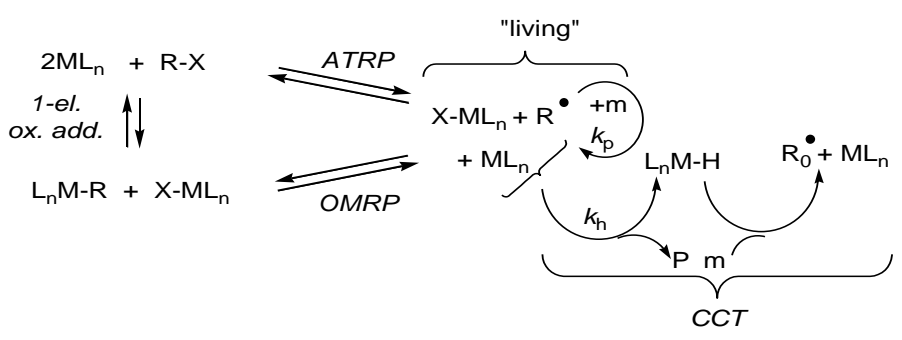

\section{Scheme 3}

In subsequent work, we have extended the family of half-sandwich $\mathrm{Mo}^{\mathrm{III}}$ species to complexes containing substituted diazabutadiene $\left(\mathrm{R}_{2} \mathrm{dad}\right)$ ligands $[5,21]$. The latter ligands have the advantage of being air stable and more easily accessible than the substituted phosphine ligands, thus giving access to a large range of complexes with tuneable steric and electronic properties. We have already reported the effectiveness of $\mathrm{CpMoCl}_{2}\left(\mathrm{Ar}_{2} \mathrm{dad}\right)(\mathrm{Ar}=$ 2,6- $\mathrm{C}_{6} \mathrm{H}_{3} \operatorname{Pr}_{2}^{\mathrm{i}}$ ) in both the OMRP and the ATRP of styrene [21], whereas the corresponding $i \operatorname{Pr}_{2}$ dad complex was shown to be capable of controlling the polymerization of styrene, methyl acrylate (MA), and butyl acrylate, under ATRP conditions. The MA polymerization under ATRP conditions was shown to be accelerated by the presence of the $\mathrm{Al}\left(\mathrm{OPr}^{\mathrm{i}}\right)_{3}$ cocatalyst, and a PMA- $b$-PS block co-polymer could be obtained [5].

During this previously reported investigation, we have occasionally witnessed very low initiator efficiency factors $(f)$. The initiator efficiency factor describes how effectively the initiator is capable to give rise to polymer chains. Ideally, each initiator molecule gives rise to only one chain $(f=1)$. When a fraction of the initiator molecules does not produce growing polymer chains, then the average polymer $\mathrm{M}_{\mathrm{n}}$ at a given conversion is greater than expected, whereas lower $\mathrm{M}_{\mathrm{n}}$ than expected are a consequence of processes that generate additional chains (i.e. chain transfer, self-initiation). There are two well recognized phenomena leading 
to low efficiency factors. A slow initiation process $\left(e . g\right.$. when $\left.k_{0+}<<k_{1+}, k_{2+}, \ldots k_{\mathrm{n}+}\right)$ initially yields a fraction of chains whose propagation rate is more rapid than the activation of the residual initiator molecules. This results in initially higher $\mathbf{M}_{\mathrm{n}}$ than expected (i.e. low $f$ ) and to a broad polydispersity. However, the remainder of the initiator molecules do eventually activate, thus $f$ tends to 1 and the polydispersity index (PDI) decreases as the polymerization progresses. The second phenomenon is a low spin trapping rate. Under these conditions, the active radical concentration is initially too large, favoring uncontrolled chain growth and bimolecular terminations. Thus, here also, large PDI and low $f$ are initially observed. This situation may eventually be corrected by the persistent radical effect, thus the polymerization may ultimately become controlled and the PDI will decrease. However, the terminated polymer chains cannot be reactivated and $f$ remains low throughout the polymerization. For $\mathrm{Cu}(\mathrm{I})$-catalyzed ATRP, measurements of the concentration of the $\mathrm{Cu}(\mathrm{II})$ spin trap that accumulates during the polymerization process have shown that up to $10-15 \%$ of initiator molecules may be consumed by bimolecular terminations [22]. This means that an equivalent fraction of initiator molecules will generate dead chains ( $f$ down to 0.9-0.85).

The observations reported in our previous paper [5] did not seem consistent with either of the above explanations. This is because quite low $f$ values (down to 0.55 ) have been observed and remain low throughout the polymerization process, while the PDI is relatively low even at the beginning of the process. In addition, under comparable conditions, $\mathrm{CpMoCl}_{2}\left(i \mathrm{Pr}_{2} \mathrm{dad}\right)$ yields a low efficiency factor $(0.85$ for the polymerization of styrene in bulk with $\mathrm{BEB}$ initiator at $\left.90^{\circ} \mathrm{C}\right)$ whereas other $\mathrm{CpMoCl}_{2}\left(\mathrm{R}_{2} \mathrm{dad}\right)$ catalysts $(\mathrm{R}=\mathrm{Ph}, p$-Tol, 2,6-i $\operatorname{Pr}_{2} \mathrm{C}_{6} \mathrm{H}_{3}$ ) yield $f=1$. This result does not seem consistent with a low trapping rate, because the sterically more encumbering 2,6-i $\operatorname{Pr}_{2} \mathrm{C}_{6} \mathrm{H}_{3}$-substituted system should in principle yield a more hindered atom transfer process. It is relevant to note here that low efficiency factors have also sometimes been observed for other systems, but they are not systematically 
underlined nor their explanation is attempted $[6,7,23]$. We have consequently decided to further explore this issue, and the results of our studies are reported herein.

\section{Experimental Section}

General procedures. (a) Chemicals. Styrene was washed with an aqueous $\mathrm{NaOH}$ solution (10\%), followed by water, then dried over $\mathrm{MgSO}_{4}$ and finally distilled at $25^{\circ} \mathrm{C}$ under reduced pressure. Methyl acrylate was passed through an alumina column and then distilled under argon. Toluene was purified by distillation under argon after drying over sodium benzophenone ketyl. $\mathrm{Al}\left(\mathrm{OPr}^{\mathrm{i}}\right)_{3}($ Aldrich) was used as received and handled in a glovebox under dry and oxygen-free argon. AIBN (JANSSEN) was recrystallized twice from $\mathrm{MeOH}$ before use. Compounds $\mathrm{CH}_{3} \mathrm{CHClCOOEt}$ (ClEA) and $\mathrm{CH}_{3} \mathrm{CHBrCOOEt}$ (BrEA) were purchased from Aldrich and used as received. Compounds $\mathrm{CpMoCl}_{2}\left(\mathrm{Pr}_{2} \mathrm{dad}\right)$ [21] and ethyl 2-iodo-propionate (IEA) [24] were obtained according to previously described synthetic procedures.

(b) Measurements. EPR measurements were carried out at the X-band microwave frequency on a Bruker ESP300 spectrometer. The spectrometer frequency was calibrated with diphenylpicrylhydrazyl (DPPH, g = 2.0037). Cyclic voltammograms were recorded with an EG\&G 362 potentiostat connected to a Macintosh computer through MacLab hardware/sofware. The electrochemical cell was fitted with an $\mathrm{Ag}-\mathrm{AgCl}$ reference electrode, a platinum disk working electrode and a platinum wire counter-electrode. $\left[\mathrm{Bu}_{4} \mathrm{~N}\right] \mathrm{PF}_{6}(\mathrm{ca} .0 .1$ M) was used as supporting electrolyte in THF. All potentials are reported relative to the ferrocene standard, which was added to each solution and measured at the end of the experiments. The MW distribution, $\mathrm{M}_{\mathrm{n}}$ and $\mathrm{M}_{\mathrm{w}} / \mathrm{M}_{\mathrm{n}}$ of the polymers were measured by sizeexclusion chromatography (SEC) using THF as eluent $(1 \mathrm{~mL} / \mathrm{min})$ at room temperature on 
two polystyrene gel columns (B Jordi) equipped with a refractive index detector. The columns were calibrated against standard polystyrene and PMMA (Polymer Laboratories). The $\mathrm{M}_{\mathrm{n}}$ of PMA was corrected from the PMMA calibration by using Mark-Houwink coefficients [5, 25].

Synthesis of CpMoI $2\left(\operatorname{Pr}_{2}{ }_{2}\right.$-dad). Complex $\mathrm{CpMoCl}_{2}\left(\operatorname{Pr}_{2}{ }_{2} \mathrm{dad}\right)(260 \mathrm{mg}, 0.70 \mathrm{mmol})$ and anhydrous NaI (1.05 g, $7.00 \mathrm{mmol})$ were placed in a flask together with THF (20 mL) and a magnetic stirrer bar. The mixture was stirred at $50^{\circ} \mathrm{C}$ and aliquot were periodically withdrawn for EPR monitoring. The physical aspect of the reaction mixture did not change during the transformation (suspension of a white solid in a brown solution). A complete transformation occurred in $2 \mathrm{~h}$ (see Results section). The final mixture was evaporated to dryness under reduced pressure and the residue was extracted with toluene $(25 \mathrm{~mL})$. After filtration, the product was concentrated and recovered by precipitation with heptane $(40 \mathrm{~mL})$. Then, the solid is washed with heptane $(2 \times 5 \mathrm{~mL})$ and dried under vaccum. Yield: $35 \mathrm{mg}, 9$ \%. Anal. Calcd for $\mathrm{C}_{13} \mathrm{H}_{21} \mathrm{I}_{2} \mathrm{MoN}_{2}$ : C, 28.13; H, 3.81; N, $5.05 \%$. Found: C: $28.55 ; \mathrm{H}: 3.51$ $\mathrm{N}: 5.33 \%$. EPR (THF): $\mathrm{g}=2.042$. Cyclic voltammetry $(\mathrm{THF})$ : irreversible oxidation at $\mathrm{E}_{\mathrm{p}, \mathrm{a}}$ $=0.17 \mathrm{~V}$. The low yield of the isolated product is related to the relative solubility in the solvent combination used for crystallization, while the halide exchange reaction is quantitative (by EPR monitoring, see Results section). These conditions were used in order to isolate an analytically pure product. For the purpose of carrying out the polymerization studies, the toluene solutions obtained from the extraction procedure could be used directly after filtration. The single crystals used for the X-ray investigation were obtained by slowly cooling a saturated toluene solution to $-30^{\circ} \mathrm{C}$.

Polymerizations. (a) Under ATRP conditions. All ATRP polymerisation reactions were conducted following the same experimental procedure. A typical procedure is described as a representative example. $\mathrm{CpMoCl}_{2}\left(\mathrm{Pr}_{2} \mathrm{dad}\right)$ and $\mathrm{Al}\left(\mathrm{OPr}^{\mathrm{i}}\right)_{3}$ were added to a $25 \mathrm{~mL}$ Schlenk 
tube equipped with a stirring bar. Styrene, toluene and 2-iodopropionate were added to the reaction flask by a syringe after a 20 min Ar purge. The Schlenk tube was immersed in an oil bath heated at $90^{\circ} \mathrm{C}$. Aliquots were withdrawn periodically for monitoring by SEC.

(b) Under OMRP conditions. All OMRP polymerizations were conducted as follows: appropriate amounts of the Mo complex and $\alpha, \alpha$-azoisobutyronitrile (AIBN) were added to a $50 \mathrm{~mL}$ Schlenk tube equipped with a magnetic stirring bar. Styrene or MA was added by a syringe. The Schlenk tube was immersed in an oil bath heated at $100^{\circ} \mathrm{C}$. Aliquots were withdrawn periodically for a reaction monitoring by SEC.

\section{Single crystal X-ray diffraction studies for compounds $i$ Pr2dad and}

CpMoI 2 (iPr2dad). The structure of $\mathrm{CpMoI}_{2}\left(i \mathrm{Pr}_{2} \mathrm{dad}\right)$ has recently been communicated [26] (CCDC 243377) and full details are reported here. Intensity data were collected for both compounds on a Nonius Kappa CCD at $110 \mathrm{~K}$. The structures were solved by direct method for $i \operatorname{Pr}_{2}$ dad and via a Patterson search program for $\mathrm{CpMoI}_{2}\left(i \operatorname{Pr}_{2} \mathrm{dad}\right)$ and refined with fullmatrix least-squares methods based on $F^{2}$ (SHELXL-97) [27] with the aid of the WINGX program [28]. All non-hydrogen atoms were refined with anisotropic thermal parameters. Hydrogen atoms were either included in their calculated positions and refined with a riding model for $\mathrm{CpMoI}_{2}\left(i \mathrm{Pr}_{2} \mathrm{dad}\right)$ or found in the final difference Fourier maps and freely refined for $i \operatorname{Pr}_{2} \mathrm{dad}$. The crystal data and refinement parameters are listed in Table 1 and selected bond distances and angles are collected in Table 2 for compound $i \operatorname{Pr}_{2}$ dad and in Table 3 for compound $\mathrm{CpMoI}_{2}\left(i \mathrm{Pr}_{2} \mathrm{dad}\right)$. Crystallographic data (excluding structure factors) of the $i \mathrm{Pr}_{2}$ dad compound have been deposited with the Cambridge Crystallographic Data Centre as supplementary publication no. CCDC 624422. Copies of the data can be obtained free of charge on application to the Director, CCDC, 12 Union Road, Cambridge CB2 1EZ, UK (fax: (+44) 1223-336-033; e-mail: deposit@ccdc.cam.ac.uk). 
<Table 1, Table 2 and Table 3 here>

\section{Results and Discussion}

(a) Synthesis and characterization of complex $\mathrm{CpMoI}_{2}(i \operatorname{Pr} 2 \mathrm{dad})$.

The reaction of $\mathrm{CpMoCl}_{2}\left(i \mathrm{Pr}_{2}\right.$ dad $)$ with excess $\mathrm{NaI}$ in THF proceeds to full exchange of both halide positions, see Equation 1. This synthesis has been recently communicated, but full details are reported here [26]. An EPR monitoring of the reaction indicates that the process is quantitative and stepwise, with the observable generation of an intermediate species which must be the mixed halogen complex $\mathrm{CpMoICl}\left(i \mathrm{Pr}_{2} \mathrm{dad}\right)$. This intermediate complex shows an EPR resonance whose position $(\mathrm{g}=2.010)$ and lineshape are midway between those of the starting complex $(g=1.977)$ and final product $(g=2.042)$, see Figure 1 . This synthesis parallels the procedure used to convert $\mathrm{CpMoCl}_{2}\left(\mathrm{PMe}_{3}\right)_{2}$ to the corresponding diiodo derivative. In that case, the intermediate mixed halide complex could also be isolated and structurally characterized [29].

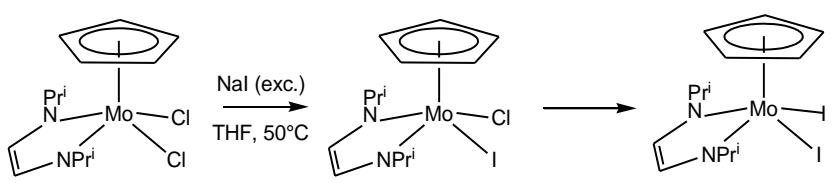

\section{Equation 1}




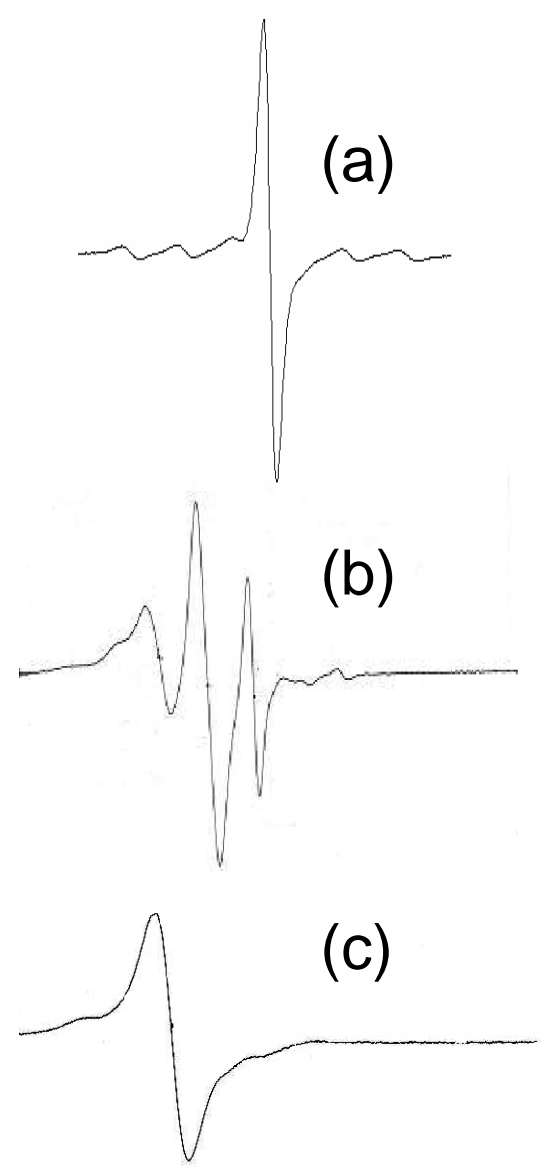

Figure 1. EPR spectrum evolution during the synthesis of complex $\mathrm{CpMoI}_{2}\left(i \mathrm{Pr}_{2} \mathrm{dad}\right)$. Conditions: $\mathrm{CpMoCl}_{2}\left(i \mathrm{Pr}_{2} \mathrm{dad}\right)+5$ equiv of $\mathrm{NaI}, \mathrm{THF}$ as solvent, room temperature. (a) Initial spectrum; (b) after $20 \mathrm{~min}$; (c) after $2 \mathrm{~h}$.

Like its dichloride precursor, complex $\mathrm{CpMoI}_{2}\left(i \mathrm{Pr}_{2} \mathrm{dad}\right)$ is redox active, showing an irreversible one-electron oxidation process in THF with an anodic peak potential at $\mathrm{E}_{\mathrm{p}, \mathrm{a}}=0.17$ $\mathrm{V}$ relative to ferrocene. The irreversibility of the $\mathrm{CpMoI}_{2}\left(\mathrm{Pr}_{2} \mathrm{dad}\right)$ oxidation contrasts with the reversibility shown by the dichloride precursor (oxidation at $\mathrm{E}_{1 / 2}=0.01 \mathrm{~V}$, see a comparison in Figure 2) and signals a greater instability for the 16-electron $\left[\mathrm{CpMoI}_{2}\left(i \mathrm{Pr}_{2} \mathrm{dad}\right)\right]^{+}$complex relative to the dichloro derivative. The follow-up chemical process that decomposes the product of one-electron oxidation must have the effect of shifting the anodic peak potential in the negative direction, thus the thermodynamic oxidation potential $\left(\mathrm{E}_{1 / 2}\right)$ of the diiodo derivative must necessarily be greater than that of the dichloride. 


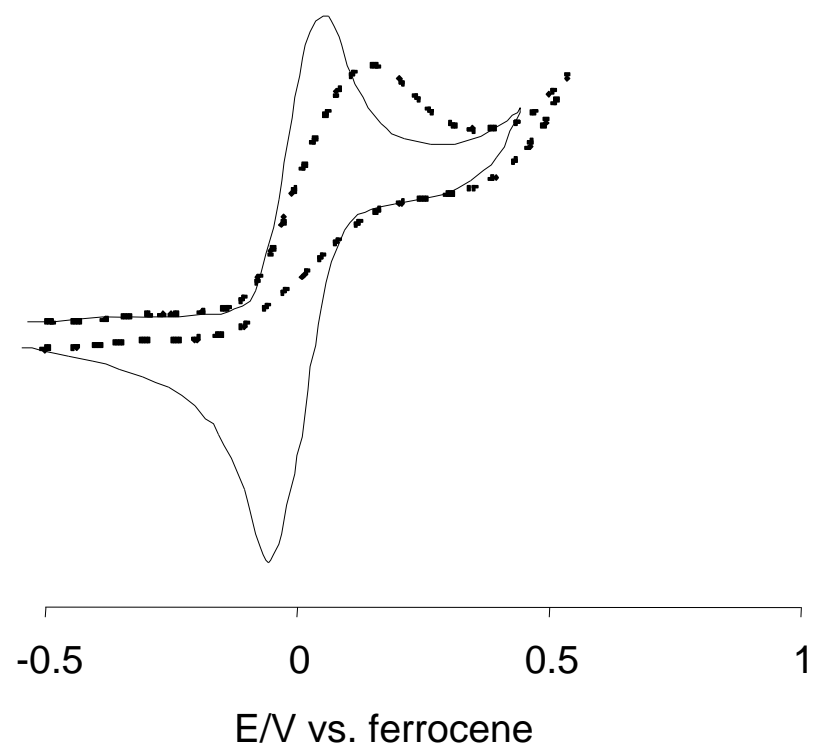

Figure 2. Room temperature cyclic voltammograms of complexes $\mathrm{CpMoCl}_{2}\left(i \mathrm{Pr}_{2}\right.$ dad) (plain line) and $\mathrm{CpMoI}_{2}\left(i \mathrm{Pr}_{2} \mathrm{dad}\right)$ (dashed line) in THF.

The molecular structure of $\mathrm{CpMoI}_{2}\left(i \mathrm{Pr}_{2} \mathrm{dad}\right)$, as determined from a single crystal X-ray diffraction study, shows the ubiquitous four-legged piano stool geometry, see Figure 3. The molecule sits on a crystallographic mirror plane which contains the Mo atom and the Cp ring centroid, and passes through the midpoint of the $\mathrm{C}(4)-\mathrm{C}(4) \#$ bond. This imposes planarity to the dad ligand $\mathrm{N}_{2} \mathrm{C}_{2}$ core. The Mo atom is also essentially coplanar with the dad plane, the deviation being only 0.129(6) $\AA$. The dihedral angle between the $\mathrm{N}_{2} \mathrm{C}_{2}$ and $\mathrm{N}_{2}$ Mo planes is only $4.5^{\circ}$, i.e. smaller than the same angle in the related complex $\mathrm{CpMoCl}_{2}\left(\mathrm{Ar}_{2} \mathrm{dad}\right)(\mathrm{Ar}=2,6-$ $\left.\mathrm{C}_{6} \mathrm{H}_{3} \operatorname{Pr}_{2}{ }_{2}\right)$ [21]. It is also interesting to observe that the N-C and C-C distances of the dad ligand are respectively longer and shorter, when compared with those of free dad molecules such as s-trans-Cy 2 dad (N-C: $1.258(3) \AA$; C-C: $1.457(3) \AA$ ) [30] and s-trans-Bu ${ }_{2}^{\mathrm{t}}$ dad (N-C: 1.269(2) $\AA$; C-C: $1.477(2) \AA$ ) [31] and also with those of complexes where the ligand may be viewed as binding in the neutral diazadiene form (N-C: $1.26-1.30 \AA$; C-C: $1.40-1.46 \AA$ ) [32]. They are typical of the binding mode as an enediamido ligand. In comparison, these distances are even longer and shorter, respectively, in the above mentioned $\mathrm{CpMoCl}_{2}\left(\mathrm{Ar}_{2} \mathrm{dad}\right)$ complex (C1-N, 1.352(2) $\AA$; C1-C1\#, 1.363(2) $\AA$ ), indicating that the enediamido character is more 
pronounced in the dichloride complex. In other words, the metal atom transfers more electron density to the diazadiene ligand in the dichloride complex. The Mo-I distances are close to those of the related $\mathrm{CpMoI}_{2}\left(\mathrm{PMe}_{3}\right)_{2}$ complex (2.831(1) $\AA$ ) [33].

We have also measured the structure of the free $i \operatorname{Pr}_{2}$ dad ligand, see Figure 4 . The molecule adopts a s-trans conformation with C-N and C-C distances of 1.2729(18) and 1.466(3) $\AA$, respectively, typical of $\alpha$-diimine compounds. These parameters are similar to those previously determined for other $\mathrm{R}_{2}$ dad and analogues (e.g. $\mathrm{R}=\mathrm{Cy}$ [30], $t \mathrm{Bu}[31], 2,6-$ $i \operatorname{Pr}_{2} \mathrm{C}_{6} \mathrm{H}_{3}$ [34], Mes [35], $\mathrm{CH}_{2} \mathrm{Ph}$ [36], and $\mathrm{CH} i \mathrm{Pr}_{2}$ [36]).

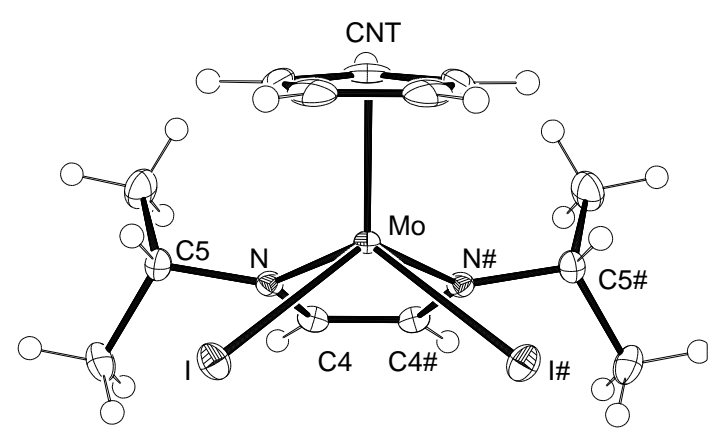

Figure 3. An ORTEP view of compound $\mathrm{CpMoI}_{2}\left(i \mathrm{Pr}_{2} \mathrm{dad}\right)$.

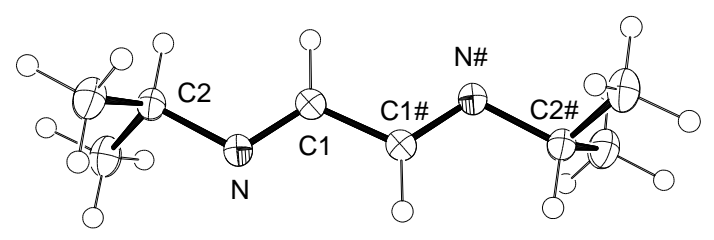

Figure 4. An ORTEP view of compound $i \operatorname{Pr}_{2}$ dad.

(b) MA polymerizations under ATRP conditions.

In previous contributions, we have already reported the MA and S polymerization under ATRP conditions catalyzed by complex $\mathrm{CpMoCl}_{2}\left(i \operatorname{Pr}_{2}\right.$ dad $)[5,21]$. The MA polymerization 
was conveniently achieved using IEA as initiator and in the presence of $\mathrm{Al}\left(\mathrm{OPr}^{\mathrm{i}}\right)_{3}$ as cocatalyst in toluene $(30 \% \mathrm{v} / \mathrm{v}$ of $\mathrm{MA})$ at $80^{\circ} \mathrm{C}$, since the polymerization rate was too slow in the absence of the $\mathrm{Al}$ compound, and a polymerization carried out with the BrEA initiator was slower still. The observed $f$ was $0.85\left(0.6\right.$ in the absence of co-catalyst at $\left.100^{\circ} \mathrm{C}\right)$ [5]. For the polymerization of styrene, convenient rates were achieved without the need of a co-catalyst using BEB as initiator at $90^{\circ} \mathrm{C}$ in bulk. The observed $f$ in this case was 0.85 [21]. Styrene polymerization was also achieved with the IEA initiator in the presence of $\mathrm{Al}\left(\mathrm{OPr}^{\mathrm{i}}\right)_{3}$ as cocatalyst in toluene $(30 \% \mathrm{v} / \mathrm{v}$ of $\mathrm{S})$ at $90^{\circ} \mathrm{C}$. Under these conditions, an $f$ value of 0.55 was observed [5]. It is interesting to observe that, contrary to $\mathrm{CpMoCl}_{2}\left(i \operatorname{Pr}_{2} \mathrm{dad}\right)$, the related complexes containing aryl-substituted ligands $\left(\mathrm{Ar}_{2}\right.$ dad with $\mathrm{Ar}=\mathrm{Ph}, p$-Tol and 2,6- $\left.\mathrm{C}_{6} \mathrm{H}_{3} \operatorname{Pr}_{2}{ }_{2}\right)$ gave PS with slightly lower $\mathrm{M}_{\mathrm{n}}$ than theory, as might be expected from a minor contribution of self-initiation or chain transfer processes. This is a quite relevant observation and we shall come back to it after presenting the new results of our study. For the polymerizations carried out with the $i \operatorname{Pr}_{2}$ dad complex, the $f$ values mentioned above should be considered upper limits, since the intervention of chain transfer would artificially raise the experimentally determined $f$ value relative to a transfer-free, pseudo-living process.

We have now carried out additional ATRP experiments on MA, the conditions and results being shown in Table 4. Since the previously reported polymerizations were carried out only with mixed halogen systems $\left(\mathrm{CpMoCl}_{2}\left(\mathrm{R}_{2} \mathrm{dad}\right)+\mathrm{XEA}\right.$ with $\mathrm{X}=\mathrm{Br}$ or I $)$ and since the chemistry may be complicated by halogen exchange processes [26, 37], it was important to also carry out polymerizations with systems containing the same halogen atom on both the Mo complex and the initiator molecule. Using the 1-Cl-substituted ethyl propionate (ClEA) as initiator and the Mo dichloride complex, the polymerization is too slow to measure when carried out without $\mathrm{Al}\left(\mathrm{OPr}^{\mathrm{i}}\right)_{3}$ (no significant amount of polymer was observed after $48 \mathrm{~h}$ ). However, a polymerization with a measurable rate was achieved in the presence of the co- 
catalyst. This polymerization occurs in a pseudo-living fashion with $\mathrm{M}_{\mathrm{n}}$ growing linearly with the conversion, although the resulting polymer has relatively high PDI (ca. 1.5). The result previously reported with $\mathrm{CpMoCl}_{2}\left(i \operatorname{Pr}_{2} \mathrm{dad}\right)+\mathrm{IEA}$ is also listed in Table 4 for comparison. It can be noted that the apparent rate constant increases by a factor of ca. 10 upon changing the initiator from ClEA to IEA. The most remarkable result, however, is that $f$ is 0.37 when using the chloride initiator, i.e. the lowest value that we have observed so far in our laboratory.

$<$ Table 4>

Moving now to the fully iodine-based system, the polymerization is relatively slow when carried out in the absence of $\mathrm{Al}\left(\mathrm{OPr}^{\mathrm{i}}\right)_{3}$, but becomes the fastest amongst all those reported in Table 4 when carried out in the presence of the co-catalyst. Thus, the ATRP of MA is accelerated also by replacing $\mathrm{Cl}$ by $\mathrm{I}$ in the Mo catalyst (by a factor of ca. 5). The polymerization still retains a pseudo-living character in both cases with linear $M_{n}$ vs. conversion plots and quite low PDI (e.g. see Figure 5 for the experiment carried out in the presence of co-catalyst). Most importantly, however, the experimental $\mathrm{M}_{\mathrm{n}}$ are rather close to (in fact, slightly smaller than) the theoretical values. Thus, we may assume that $f$ is unity for this system, the slight deviation toward smaller $\mathrm{M}_{\mathrm{n}}$ being possibly caused by a small extent of catalyzed chain transfer. The alternative possibility of self initiation may be safely discarded in this case because, contrarily to styrene, methyl acrylate is not apt to self initiate a radical polymerization under these experimental conditions. 


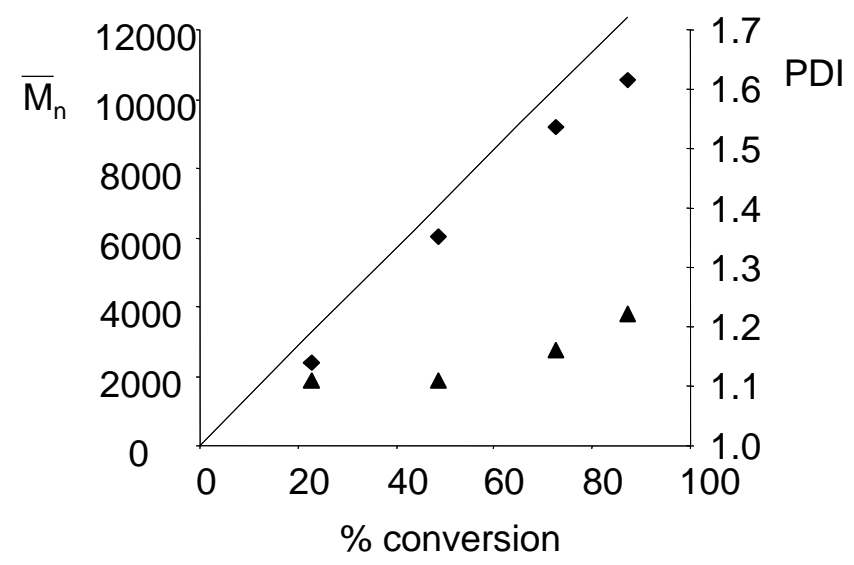

Figure 5. Experimental $\overline{\mathrm{M}_{\mathrm{n}}}$ (diamonds) and PDI (triangles) as a function of conversion for the MA polymerization in the presence of $\mathrm{CpMoI}_{2}\left(i \mathrm{Pr}_{2} \mathrm{dad}\right) / \mathrm{IEA} / \mathrm{Al}(\mathrm{O} i \mathrm{Pr})_{3}$ (experimental conditions as reported in Table 4). The straight line shows the theoretical $\mathrm{M}_{\mathrm{n}}$.

(c) S and MA polymerizations under OMRP conditions.

A key for understanding the origin of the low $f$ values for some ATRP processes and not for others comes from complementary polymerization studies carried out under OMRP conditions. We have previously shown that complex $\mathrm{CpMoCl}_{2}\left(\mathrm{Ar}_{2} \mathrm{dad}\right)$ with $\mathrm{Ar}=2,6-$ $\mathrm{C}_{6} \mathrm{H}_{3} \operatorname{Pr}_{2}{ }_{2}$ is capable of controlling the polymerization of styrene initiated by the thermal decomposition of AIBN [21]. We recollect here that the same complex affords PS under ATRP conditions with $f=$ ca. 1 . Styrene polymerization was not previously tested under the same conditions for any of the other $\mathrm{R}_{2}$ dad complexes.

We now report the result of the AIBN-initiated styrene polymerization in the presence of $\mathrm{CpMoCl}_{2}\left(i \mathrm{Pr}_{2} \mathrm{dad}\right)$, see Figure 6. Although this polymerization starts with an effective rate close to that of the similar $\mathrm{CpMoCl}_{2}\left[\left(2,6-i \mathrm{Pr}_{2} \mathrm{C}_{6} \mathrm{H}_{3}\right)_{2} \mathrm{dad}\right]$ complex [21] (also shown in Figure 6 for comparison), it stops at a conversion of ca. $15 \%$ after an initial activity period that lasts ca. $100 \mathrm{~min}$. Continued monitoring for an additional $10 \mathrm{~h}$ did not show any further conversion beyond $15 \%$. On the other hand, the polymerization continues in a controlled fashion to much higher conversions in the presence of the 2,6-i $\operatorname{Pr}_{2} \mathrm{C}_{6} \mathrm{H}_{3}$-substituted derivative, as reported previously [21]. The obvious conclusion of this experiment is that a parallel 
reaction, consuming irreversibly the OMRP dormant species, occurs within the first $100 \mathrm{~min}$ of the polymerization process for the $i \operatorname{Pr}_{2}$ dad derivative. On the other hand, the 2,6$i \operatorname{Pr}_{2} \mathrm{C}_{6} \mathrm{H}_{3}$ dad derivative is more stable on the same timescale and continues to reversibly generate the reactive radicals. An even more striking result was obtained for the AIBNinitiated OMRP of MA in the presence of $\mathrm{CpMoCl}_{2}\left(i \mathrm{Pr}_{2} \mathrm{dad}\right)$. In this case, the experiment produced no PMA whatsoever! This shows that the irreversible consumption of the OMRP dormant species is even more rapid for the PMA growing chain.

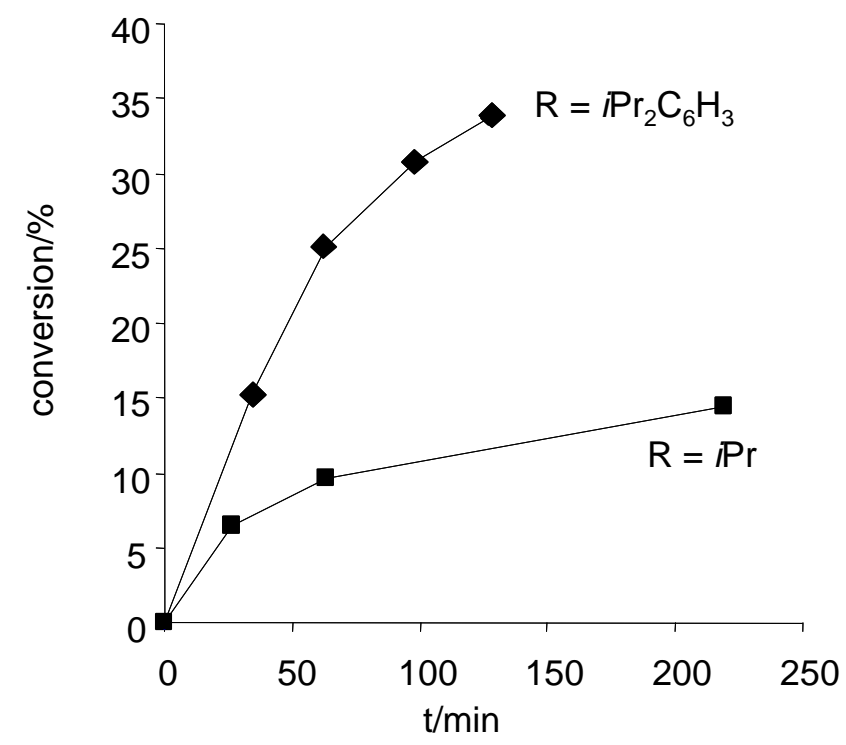

Figure 6. Conversion vs. time for the polymerization of styrene initiated by AIBN in the presence of $\mathrm{CpMoCl}_{2}(\mathrm{R} 2 \mathrm{dad})$ in bulk at $100^{\circ} \mathrm{C}$.

The OMRP of styrene and MA with the diiodide complex $\mathrm{CpMoI}_{2}\left({ }_{2} \operatorname{Pr}_{2} \mathrm{dad}\right)$, on the other hand, give rise to a polymerization process. The polymerization does not have the typical characteristics of a controlled polymerization. The monomer consumption is fast initially, especially in the case of MA $\left(62 \%\right.$ conversion in the first $2 \mathrm{~h}$ in bulk at $\left.90^{\circ} \mathrm{C}\right)$, but subsequently slows down, and the final polymer isolated at $73 \%$ conversion $(5 \mathrm{~h})$ has an average $M_{n}$ rather close to the theoretical one for one chain per Mo center $\left(4.06 \cdot 10^{4} v s\right.$. $\left.3.24 \cdot 10^{4} \mathrm{~g} \mathrm{~mol}^{-1}\right)$ and the polydispersity index is rather low (1.23). Thus, the active radicals 
do not seem to be irreversibly trapped by the Mo complex. Rather, the formation of the $\mathrm{Mo}^{\mathrm{IV}}$ $\mathrm{R}$ bond is not sufficiently favoured from the thermodynamic or kinetic point of view to yield a controlled process. Therefore, this system operates just like the previously reported $\mathrm{CpMoCl}_{2} \mathrm{~L}_{2}\left(\mathrm{~L}=\mathrm{PMe}_{3}\right.$ or $\left.\mathrm{L}_{2}=\mathrm{dppe}\right)$ compounds under ATRP conditions [4]: the ATRP equilibrium is suitably placed thermodynamically to ensure a good control and the OMRP equilibrium also contributes to trap the reactive radicals of the growing chains, thereby further reducing their concentration and helping in the control mechanism (though, in this case, the compound is not capable of ensuring a good control by itself under OMRP conditions). As discussed in a recent Minireview [13], when the process is set up under ATRP conditions there may be an interplay of the two control mechanisms (ATRP and OMRP), but the nature of the isolated polymer is dictated by the thermodynamics, therefore the relative proportion of the two mechanisms cannot be revealed by analyzing the polymer (for instance, the chain ends). On the other hand, when the process is set up under OMRP conditions, only the OMRP equilibrium can operate because the ATRP spin trap is not formed.

A tentative hypothesis to rationalize the above observations is that the more sterically encumbered complexes (the $\operatorname{Ar}_{2}$ dad dichloride derivative, or the $i \operatorname{Pr}_{2}$ dad diiodide derivative) form only weak $\mathrm{Mo}^{\mathrm{IV}}-\mathrm{R}$ bonds and therefore act as reversible spin traps (Scheme 4), whereas the less encumbered $i \operatorname{Pr}_{2}$ dad dichloride complex traps the growing radical chains irreversibly. However, the slower (ca. $100 \mathrm{~min}$ ) deactivation of the $\mathrm{CpMoCl}_{2}\left(i \mathrm{Pr}_{2} \mathrm{dad}\right)$-PS dormant chains rather suggests that trapping by the OMRP equilibrium is reversible even in this case, but is followed by a slow and irreversible decomposition to other products (see Scheme 5). These hypotheses need verification by independent syntheses and characterization of the products, which we are planning for the immediate future. As a first attempt at characterizing the OMRP dormant chain, we have thermally decomposed an AIBN solution in the presence of $\mathrm{CpMoCl}_{2}\left(i \mathrm{Pr}_{2} \mathrm{dad}\right)$ solution but in the absence of monomer. The spectroscopic monitoring of 
this reaction shows only the formation of the same organic products that are generated from AIBN in the absence of the Mo complex. Therefore, the metal complex is not a sufficiently good trap for the tertiary $\left(\mathrm{CH}_{3}\right)_{2} \mathrm{C}(\mathrm{CN})$ radicals generated by AIBN.

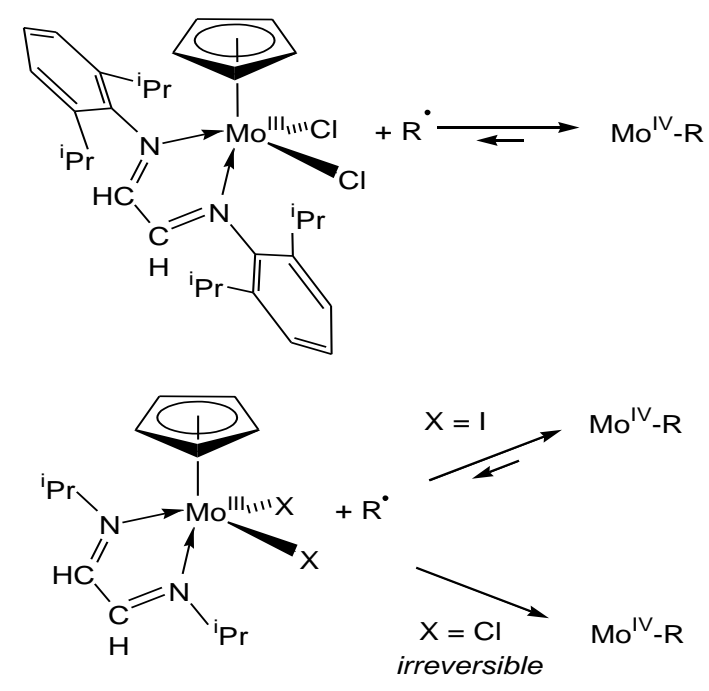

Scheme 4

$$
\begin{aligned}
\mathrm{CpMo}^{\mathrm{III}} \mathrm{X}_{2}\left(i \mathrm{Pr}_{2} \text { dad }\right)+ & \mathrm{R}^{\cdot} \longrightarrow \mathrm{CpMo}^{\mathrm{IV}} \mathrm{X}_{2}(\mathrm{R})\left(\mathrm{Pr}_{2} \text { dad }\right) \\
& \stackrel{\text { only for } \mathrm{X}=\mathrm{Cl}}{\longrightarrow} \text { decomposition } \\
& \begin{array}{l}
\text { slow for } \mathrm{m}=\mathrm{S} \\
\text { fast for } \mathrm{m}=\mathrm{MA}
\end{array}
\end{aligned}
$$

\section{Scheme 5}

(d) Intermezzo: a mechanistic discussion.

The observed efficiency factors can now be rationalized rather well on the basis of the global scheme introduced by us previously (Scheme 3) [4] and on the basis of the outcome of the OMRP processes. Under ATRP conditions, the Mo ${ }^{\mathrm{III}}$ catalyst produces the active radical and the $\mathrm{Mo}^{\mathrm{IV}}-\mathrm{X}$ spin trap. The atom transfer equilibrium, however, lies in favour of the catalyst plus the dormant halide-terminated polymer chain. Thus, the radical can also be efficiently trapped by the OMRP spin trap (the Mo ${ }^{\mathrm{III}}$ complex). When both equilibria are reversible, as for the previously described $\mathrm{CpMoCl}_{2} \mathrm{~L}_{2}\left(\mathrm{~L}=\mathrm{PMe}_{3}\right.$ or $\mathrm{L}_{2}=\mathrm{dppe}, \eta^{4}-\mathrm{C}_{4} \mathrm{H}_{6}$, 
$\left.\mathrm{Ar}_{2} \mathrm{dad}\right)[4,21]$, but also for $\mathrm{CpMoI}_{2}\left(i \mathrm{Pr}_{2} \mathrm{dad}\right)$, then the polymerization will occur via the ATRP and the OMRP mechanisms simultaneously and the initiator efficiency factor $f$ will turn out as 1. When, on the other hand, the OMRP trapping process is irreversible, a fraction of the growing chains is removed from the ATRP equilibrium and $f$ will consequently decrease.

(e) A verification experiment.

According to the mechanism proposed in the previous section, complex $\mathrm{CpMoCl}_{2}\left(i \mathrm{Pr}_{2} \mathrm{dad}\right)$ would be capable of irreversibly trapping the reactive radical left over by the halogen atom transfer process. The combination of the reversible ATRP activation process and the irreversible OMRP trapping processes is an irreversible 1-electron oxidative addition, see Scheme 6 [13]. Note that the stoichiometry of the 1-electron oxidative addition reaction requires the use of two equivalents of $M o^{I I I}$ complex per one of halide initiator. Note also that an alternative reversible OMRP equilibrium followed by an irreversible decomposition, as shown in Scheme 5, leads to the same overall stoichiometry for the initiator consumption. The stoichiometry used for the ATRP experiments (traditionally selected under the assumption of an uncontaminated halogen atom transfer equilibrium), on the other hand, is 1:1. This means that the occurrence of an irreversible 1-electron oxidative addition process consumes $50 \%$ of the halide initiator whereas the remaining $50 \%$ is still available to initiate polymer chains. If this is true, then using only 0.5 equivalents of initiator per Mo catalyst should lead to no polymerization.

$$
\begin{aligned}
& \mathrm{L}_{n} \mathrm{Mo}^{\prime \prime \prime}+\mathrm{R}-\mathrm{X} \longleftrightarrow \mathrm{L}_{n} \mathrm{Mo}^{\mathrm{IV}}-\mathrm{X}+\mathrm{R}^{\cdot} \\
& \mathrm{L}_{n} \mathrm{Mo}^{\prime \prime \prime}+\mathrm{R}^{\cdot} \longrightarrow \mathrm{L}_{n} \mathrm{Mo}^{\mathrm{IV}}-\mathrm{R} \\
& 2 \mathrm{~L}_{\mathrm{n}} \mathrm{Mo}^{\mathrm{III}}+\mathrm{R}-\mathrm{X} \longrightarrow \mathrm{L}_{\mathrm{n}} \mathrm{Mo}^{\mathrm{IV}}-\mathrm{X}+\mathrm{L}_{n} \mathrm{Mo}^{\mathrm{IV}}-\mathrm{R}
\end{aligned}
$$




\section{Scheme 6}

Indeed, as shown in Figure 7, an ATRP experiment of MA using $\mathrm{CpMoCl}_{2}\left(i \mathrm{Pr}_{2} \mathrm{dad}\right)$ and IEA in a 1:0.5 ratio yields no polymerization under the same experimental conditions that lead to a controlled radical polymerization with one equivalent of initiator. After 30 hours, the administration of one additional equivalent of initiator starts the polymerization process $\left(\mathrm{k}_{\mathrm{app}}\right.$ $=1.5 \times 10^{-4} \mathrm{~min}^{-1}$ ), yielding a PMA with a rather narrow MW distribution, and the observed $\mathrm{M}_{\mathrm{n}}$ are slightly smaller than the theoretical values (relative to the added equivalent of initiator). This discrepancy may again result from a minor contamination with chain transfer, but it can be safely assumed that the efficiency factor is in this case close to unity. The apparent rate constant measured for this polymerization is slightly smaller relative to the experiment where 1 equiv of initiator is present from the start (Table 4). This difference is probably related the significant intervention of halide exchange, which is catalyzed by $\mathrm{Al}\left(\mathrm{OPr}^{\mathrm{i}}\right)_{3}[26,37]$, before the initiator is completely consumed by the oxidative addition process. This exchange produces a certain amount of iodide-substituted catalyst, whose activity is greater (see Table 4). The $f$ value of 0.85 that is observed for this process is also consistent with this interpretation, since the iodide-substituted catalyst appears not to suffer from irreversible radical trapping by the OMRP mechanism.

This experiment therefore fully confirms the proposed irreversible consumption of part of the initiator when using a Mo/IEA $=1: 1$. An additional important consequence of this result is that, since all the initial $\mathrm{Mo}^{\mathrm{III}}$ catalyst has been transformed to the products of the 1electron oxidative addition (or to decomposition products thereof), it is one or more of these products that acts as the actual ATRP catalyst. This presumes that the ATRP process is taking place through $\mathrm{Mo}^{\mathrm{IV}} / \mathrm{Mo}^{\mathrm{V}}-\mathrm{X}$ redox couples. In this respect, we would like to point out that the $\mathrm{Mo}^{\mathrm{IV}}$ complexes $\mathrm{MoOX}_{2}\left(\mathrm{PMe}_{3}\right)_{2}(\mathrm{X}=\mathrm{Cl}, \mathrm{I})$ have indeed been shown to efficiently catalyze the ATRP of styrene, yielding polymers with $M_{n}$ close to theory and quite low $M_{w} / M_{n}$ [38]. 
As already mentioned above, our next investigations will aim at isolating the products of this oxidative addition process and to verify their ability to catalyze ATRP.

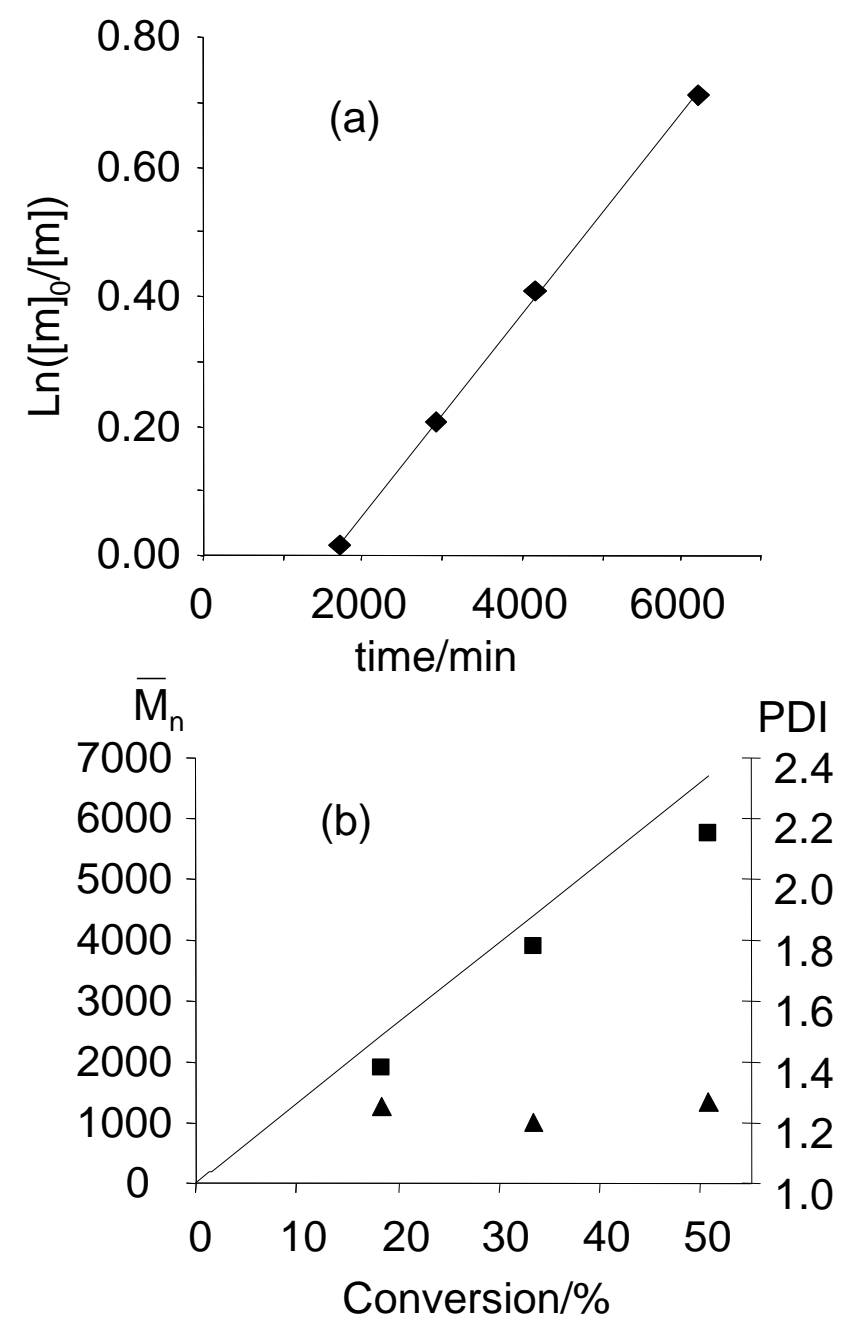

Figure 7. MA polymerization in the presence of $\mathrm{CpMoCl}_{2}\left(i \mathrm{Pr}_{2} \mathrm{dad}\right) / \mathrm{IEA} / \mathrm{Al}(\mathrm{O} i \mathrm{Pr})_{3}$ $(\mathrm{MA} / \mathrm{Mo} / \mathrm{Al} / \mathrm{IEA}=154 / 1 / 1 / 0.5+1$, see text $)$. Other experimental conditions as reported in Table 4. (a) First order kinetic plot. (b) $M_{n}$ (squares) and PDI (triangles) for the PMA product as a function of conversion.

\section{(f) Further discussion.}

A couple of observations still need to be rationalized. Oxidative addition of the halide initiator to the Mo ${ }^{\mathrm{III}}$ catalyst should consume only 0.5 equivalents per Mo atom. Therefore, the efficiency factor should not fall below 0.5 when using a Mo/initiator ratio of 1:1. 
However, we have obtained even lower $f$ values in some cases (see Table 4). It is possible, however, that one or both of the $\mathrm{Mo}^{\mathrm{IV}}-\mathrm{X}$ and $\mathrm{Mo}^{\mathrm{IV}}-\mathrm{R}$ compounds (or decomposition products thereof) are capable to undergo further irreversible reactions that consume additional halide initiator. In this respect, the MMA polymerization catalyzed by cobaltocene under ATRP conditions with ethyl 2-bromoisobutyrrate $(\mathrm{EBiB})$ as initiator was reported to proceed with $f=$ 0.25 when $\mathrm{Co} / \mathrm{RBr}=1: 1$ [39]. In that case, in accordance with the well known reactivity of cobaltocene with respect to $\mathrm{C}$-based radicals, it was proposed that the free radical $\mathrm{R}$ produced by the atom transfer process is irreversibly trapped by $\mathrm{Cp}_{2} \mathrm{Co}$ to form $\mathrm{Cp}\left(\eta^{4}-\mathrm{C}_{5} \mathrm{H}_{5} \mathrm{R}\right) \mathrm{Co}$ [39]. The overall process would lead to $\left[\mathrm{Cp}_{2} \mathrm{Co}\right] \mathrm{Br}$ and $\mathrm{Cp}\left(\mathrm{C}_{5} \mathrm{H}_{5} \mathrm{R}\right) \mathrm{Co}$ and leave $50 \%$ of the halide initiator unreacted. Thus, the initiator efficiency factor should not be lower than 0.5 if no other process occurs. One could imagine, however, that the $\mathrm{Co}^{\mathrm{I}}$ product is capable to further oxidatively add initiator to yield the $\mathrm{Co}^{\mathrm{III}}$ product $[\mathrm{CpCo}(\mu-\mathrm{Br})(\mathrm{R})]_{2}$, leaving $25 \%$ of the halide initiator still available. This reaction does not appear to be reported in the literature, but analogous oxidative additions are reported for compound $\mathrm{Co}^{\mathrm{I}} \mathrm{Me}\left(\mathrm{PMe}_{3}\right)_{4}$, to yield $\mathrm{Co}^{\mathrm{III}} \mathrm{Me}_{2} \mathrm{X}\left(\mathrm{PMe}_{3}\right)_{3}(\mathrm{X}=\mathrm{Br}, \mathrm{I})[40]$, for $\mathrm{CpCo}^{\mathrm{I}}(\mathrm{CO})_{2}$, to give $\mathrm{CpCo}^{\mathrm{III}}(\mathrm{I})(\mathrm{R})(\mathrm{CO})$ or $\left[\mathrm{CpCo}^{\mathrm{III}}(\mu-\right.$ $\mathrm{I})(\mathrm{R})]_{2}[41]$, for $\mathrm{CpCo}^{\mathrm{I}}(\mathrm{CO})\left(\mathrm{PR}_{3}\right)$, to give $\mathrm{CpCo}^{\mathrm{III}}\left(\mathrm{COR}^{\prime}\right)(\mathrm{I})\left(\mathrm{PR}_{3}\right)$ [42, 43], and for $\mathrm{CpCo}^{\mathrm{I}}\left(\mathrm{PMe}_{3}\right)_{2}$, to give $\left[\mathrm{CpCo}^{\mathrm{III}}(\mathrm{R})\left(\mathrm{PMe}_{3}\right)_{2}\right]^{+} \mathrm{I}^{-}[44]$. Clearly, additional stoichiometric studies of the alkyl halide addition to cobaltocene, as well as to the $\mathrm{CpMoCl}_{2}\left(i \mathrm{Pr}_{2}\right.$ dad $)$ system, are warranted.

It is also interesting to analyze the reason for the relatively high efficiency factor $(0.85)$ for the polymerization with $\mathrm{CpMoCl}_{2}\left(i \mathrm{Pr}_{2} \mathrm{dad}\right) / \mathrm{IEA}=1: 1$ and in the presence of $\mathrm{Al}(\mathrm{O} i \mathrm{Pr})_{3}$. If 0.5 equivalents of the initiator are trapped irreversibly by the Mo complex, then $f$ should not be greater than 0.5 . A likely explanation of this discrepancy is suggested by our parallel study of the halogen exchange process between the Mo complex and the halide initiator [26, 37], as shown in Scheme 7. If the rate of this halide exchange process competes effectively 
with the rate with which the halide initiator is irreversibly removed from the solution, then some catalytically less active dichloride complex is transformed into the catalytically more active mixed-halide and diiodide complexes, while the corresponding amount of the more effective iodide initiator is transformed into the less effective CIEA. As shown above, the diiodide molecule does not irreversibly trap the reactive radicals (results of the OMRP experiments, and $f=1$ in ATRP), and possibly the same is true for the mixed halide species. Under these conditions, only a smaller amount of initiator will be consumed irreversibly via the reaction between the dichloride complex and ClEA, and the efficiency factor will be greater than 0.5 , as observed. Furthermore, since the halide exchange process is catalyzed by $\mathrm{Al}(\mathrm{O} i \mathrm{Pr})_{3}[26,37]$, a higher initiator efficiency factor is expected in the presence of this cocatalyst with respect to the analogous experiment without co-catalyst. Indeed, the experimental evidence agrees with this prediction [5].

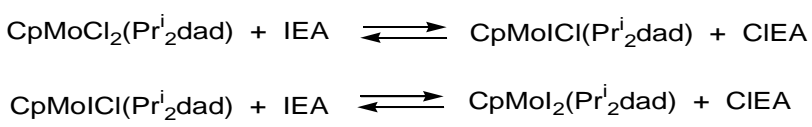

\section{Scheme 7}

It is useful to summarize here what we have learned so far on the role of $\mathrm{Al}(\mathrm{O} i \mathrm{Pr})_{3}$ as an ATRP additive. The presence of this compound boosts the polymerization rate by shifting the activation/deactivation equilibrium, e.g. the equilibrium shown in Scheme 1, to the right hand side. This effect is caused by a greater affinity of the Lewis acidic Al center for the more polar halogen atom when bonded to the more electropositive transition metal, as suggested by DFT calculations [37]. No strongly Lewis basic function is present in the OMRP equilibrium (Scheme 2), therefore the presence of $\mathrm{Al}(\mathrm{OiPr})_{3}$ is not expected to show any particular effect on OMRP. Depending on the electronic configuration around the metal center, the aluminium compound also catalyzes the halogen exchange between the halogenated transition metal 
complex (the ATRP catalyst) and the organic halide (the ATRP initiator): no catalysis occurs for the 16-electron $\mathrm{RuCl}_{2}\left(\mathrm{PPh}_{3}\right)_{2}$ complex, whereas an effect is observed for the 17-electron $\mathrm{CpMoX}_{2} \mathrm{~L}_{2}$ systems. This result has also been rationalized by DFT calculations [26, 37]. Consequently, the presence of $\mathrm{Al}(\mathrm{OiPr})_{3}$ (or any other similar Lewis acidic co-catalyst) is expected to affect the initiator efficiency factor $f$ only for mixed halogen systems (the value of $f$ should not change due to the presence of the aluminium compound for systems containing the same halogen on both catalyst and initiator), for which the halogen exchange is catalyzed by $\mathrm{Al}(\mathrm{O} i \mathrm{Pr})_{3}$ (i.e. for 17-electron complexes [37]), and at the further condition that one halogenated metal complex is capable of irreversibly trapping the reactive radicals, whereas the other one is not. In the present example, complex $\mathrm{CpMoCl}_{2}\left(i \operatorname{Pr}_{2} \mathrm{dad}\right)$ is capable of irreversibly trapping the organic radicals, whereas complex $\mathrm{CpMoI}_{2}\left(i \mathrm{Pr}_{2} \mathrm{dad}\right)$ is not.

\section{Conclusion}

The present study has served to illustrate the principle that an irreversible one-electron oxidative addition of an ATRP initiator (alkyl halide) to a transition metal complex (ATRP catalyst) is the possible cause of low efficiency factors in controlled radical polymerization. The one-electron oxidative addition reaction is the combination of the ATRP activation process (halogen atom transfer from the initiator to the catalyst) and OMRP deactivation process (formation of the metal-carbon bond). Even under conditions in which the former process is thermochemically well placed to yield a controlled polymerization process, no net polymerization results if the latter process is irreversible. The residual, unconsumed initiator molecules (just 0.5 equivalents of initiator are consumed per mole of ATRP catalyst by the one-electron oxidative addition) may still be capable to initiate a polymerization by the catalytic action of one or more of the oxidative addition products, in which case a reduced 
initiator efficiency factor will result. Therefore, the observation of unusually low initiator efficiency factors must be considered as an indication of irreversible radical trapping.

\section{Acknowledgements}

This research was sponsored by the CNRS, by the ANR (Contract No. NT05-2_42140), and by the Conseil Régional de Bourgogne through a BDI fellowship to FS.

\section{References}

[1] J.-S. Wang, K. Matyjaszewski, J. Am. Chem. Soc. 117 (1995) 5614.

[2] M. Kato, M. Kamigaito, M. Sawamoto, T. Higashimura, Macromolecules 28 (1995) 1721.

[3] Y. Kabachii, S. Kochev, L. Bronstein, I. Blagodatskikh, P. Valetsky, Polym. Bull. 50 (2003) 271.

[4] E. Le Grognec, J. Claverie, R. Poli, J. Am. Chem. Soc. 123 (2001) 9513.

[5] F. Stoffelbach, D. M. Haddleton, R. Poli, Eur. Polym. J. 39 (2003) 2099.

[6] Y. Kotani, M. Kamigaito, M. Sawamoto, Macromolecules 32 (1999) 2420.

[7] Y. Kotani, M. Kamigaito, M. Sawamoto, Macromolecules 32 (1999) 6877.

[8] V. C. Gibson, R. K. O'reilly, W. Reed, D. F. Wass, A. J. P. White, D. J. Williams, Chem. Commun. (2002) 1850.

[9] T. Ando, M. Kamigaito, M. Sawamoto, Macromolecules 33 (2000) 6732.

[10] H. Uegaki, Y. Kotani, M. Kamigaito, M. Sawamoto, Macromolecules 30 (1997) 2249.

[11] H. Uegaki, M. Kamigaito, M. Sawamoto, J. Polym. Sci., Polym. Chem. 37 (1999) 3003.

[12] J. Guo, Z. Han, P. Wu, J. Mol. Catal. A 159 (2000) 77.

[13] R. Poli, Angew. Chem., Int. Ed. Engl. 45 (2006) 5058-5070.

[14] B. B. Wayland, G. Poszmik, S. Mukerjee, J. Am. Chem. Soc. 116 (1994) 7943.

[15] A. D. Asandei, I. W. Moran, J. Am. Chem. Soc. 126 (2004) 15932.

[16] W. A. Braunecker, Y. Itami, K. Matyjaszewski, Macromolecules 38 (2005) 9402.

[17] B. B. Wayland, L. Basickes, S. Mukerjee, M. Wei, M. Fryd, Macromolecules 30 (1997) 8109

[18] Z. Lu, M. Fryd, B. B. Wayland, Macromolecules 37 (2004) 2686.

[19] S. Maria, H. Kaneyoshi, K. Matyjaszewski, R. Poli, Chem. Eur. J. (in press).

[20] K. Matyjaszewski, B. E. Woodworth, Macromolecules 31 (1998) 4718.

[21] F. Stoffelbach, R. Poli, P. Richard, J. Organometal. Chem. 663 (2002) 269.

[22] K. Matyjaszewski, J. H. Xia, Chem. Rev. 101 (2001) 2921.

[23] J. A. M. Brandts, P. Van De Geijn, E. E. Van Faassen, J. Boersma, G. Van Koten, J. Organometal. Chem. 584 (1999) 246.

[24] D. P. Curran, E. Bosch, J. Kaplan, M. Newcomb, J. Org. Chem. 54 (1989) 1826.

[25] R. A. Hutchinson, D. A. Paquet, Jr., J. H. Mcminn, S. Beuermann, R. E. Fuller, C. Jackson, DECHEMA Monographien 131 (1995) 467.

[26] F. Stoffelbach, R. Poli, Chem. Commun. (2004) 2666. 
[27] G. M. Sheldrick, SHELX97 (Includes SHELXS97 and SHELXL97), Release 97-2, Programs for Crystal Structure Analysis, University of Göttingen, Göttingen, Germany, 1998.

[28] L. J. Farrugia, J. Appl. Crystallogr. 32 (1999) 837.

[29] R. G. Linck, B. E. Owens, R. Poli, A. L. Rheingold, Gazz. Chim. Ital. 121 (1991) 163.

[30] J. Keijsper, H. Vanderpoel, L. Polm, G. Vankoten, K. Vrieze, P. Seignette, R. Varenhorst, C. Stam, Polyhedron 2 (1983) 1111.

[31] M. Haaf, A. Schmiedl, T. Schmedake, D. Powell, A. Millevolte, M. Denk, R. West, J. Am. Chem. Soc. 120 (1998) 12714.

[32] G. Van Koten, K. Vrieze, Adv. Organomet. Chem. 21 (1982) 151.

[33] S. T. Krueger, R. Poli, A. L. Rheingold, D. L. Staley, Inorg. Chem. 28 (1989) 4599.

[34] T. V. Laine, M. Klinga, A. Maaninen, E. Aitola, M. Leskela, Acta Chem. Scand. 53 (1999) 968.

[35] T. Mueller, B. Schrecke, M. Bolte, Acta Crystallogr., Sect. E: Struct. Rep. Online E59 (2003) o1820.

[36] A. Reyes-Arellano, R. Boese, I. Steller, R. Sustmann, Struct. Chem. 6 (1995) 391.

[37] R. Poli, F. Stoffelbach, S. Maria, J. Mata, Chem. Eur. J. 11 (2005) 2537.

[38] J. A. Mata, S. Maria, J.-C. Daran, R. Poli, Eur. J. Inorg. Chem. (2006) 2624-2633.

[39] B. Wang, Y. Zhuang, X. Luo, S. Xu, X. Zhou, Macromolecules 36 (2003) 9684.

[40] H.-F. Klein, H. H. Karsch, Chem. Ber. 108 (1975) 944.

[41] R. King, R. Kapoor, L. Houk, J. Inorg. Nucl. Chem. 31 (1969) 2179.

[42] A. Spencer, H. Werner, J. Organomet. Chem. 171 (1979) 219.

[43] A. Hartdavi, W. Graham, Inorg. Chem. 9 (1970) 2658.

[44] H. Werner, W. Hofmann, Chem. Ber. 110 (1977) 3481. 
Table 1. Selected crystallographic and refinement parameters for compounds $i \operatorname{Pr}_{2} \mathrm{dad}$ and $\mathrm{CpMoI}_{2}\left(i \mathrm{Pr}_{2} \mathrm{dad}\right)$.

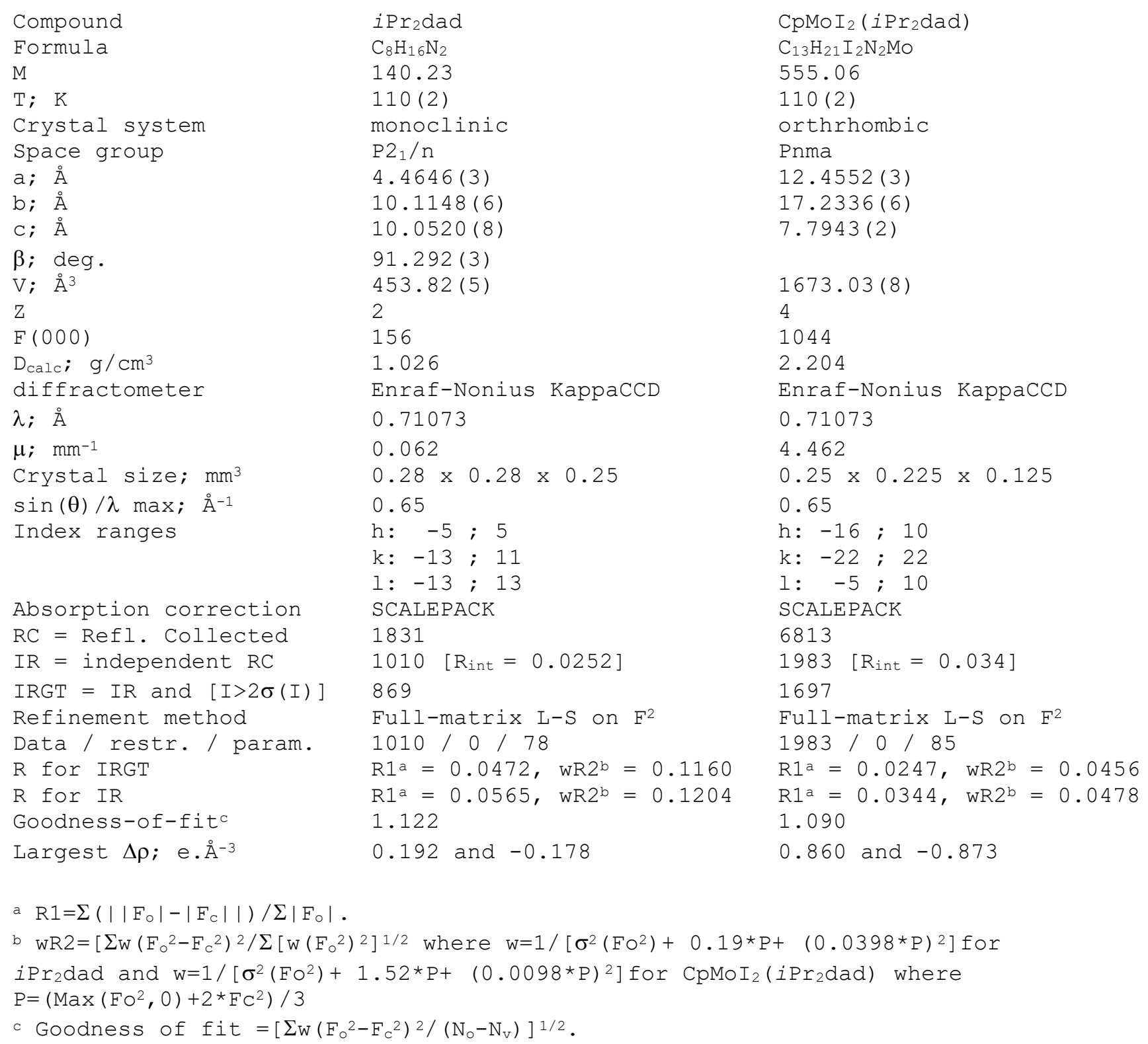


Table 2. Selected bond distances $(\AA)$ and angles $\left(^{\circ}\right)$ for $i \operatorname{Pr}_{2} \mathrm{dad}$.

\begin{tabular}{llll}
$\mathrm{N}-\mathrm{C}(1)$ & $1.2729(18)$ & $\mathrm{N}-\mathrm{C}(2)$ & $1.4677(18)$ \\
$\mathrm{C}(1)-\mathrm{C}(1) \#$ & $1.466(3)$ & $\mathrm{C}(2)-\mathrm{C}(3)$ & $1.519(2)$ \\
$\mathrm{C}(2)-\mathrm{C}(4)$ & $1.521(2)$ & & \\
\hline
\end{tabular}

\begin{tabular}{llll}
$\mathrm{C}(1)-\mathrm{N}-\mathrm{C}(2)$ & $117.10(12)$ & $\mathrm{N}-\mathrm{C}(1)-\mathrm{C}(1) \#$ & $120.33(15)$ \\
$\mathrm{N}-\mathrm{C}(2)-\mathrm{C}(3)$ & $108.90(12)$ & $\mathrm{N}-\mathrm{C}(2)-\mathrm{C}(4)$ & $108.79(12)$ \\
$\mathrm{C}(3)-\mathrm{C}(2)-\mathrm{C}(4)$ & $111.08(12)$ & & \\
& & & \\
\hline
\end{tabular}

Symmetry transformations used to generate equivalent atoms:

\#-x+1,-y,-z+2 
Table 3. Selected bond distances $(\AA)$ and angles $\left(^{\circ}\right)$ for $\mathrm{CpMoI}_{2}\left(i \operatorname{Pr}_{2} \mathrm{dad}\right) .^{\mathrm{a}}$

\begin{tabular}{llll}
\hline Mo-I & $2.8239(3)$ & Mo-N & $2.067(2)$ \\
Mo-CNT & $2.019(4)$ & N-C(4) & $1.335(3)$ \\
C(4)-C(4)\#1 & $1.372(6)$ & & \\
\hline
\end{tabular}

\begin{tabular}{lclc}
\hline & & & \\
N-Mo-N\# & $75.11(13)$ & CNT -Mo-I & $110.64(9)$ \\
N-Mo-I & $82.81(6)$ & CNT -Mo-N & $116.75(11)$ \\
N\#-Mo-I & $132.59(6)$ & I-Mo-I\# & $82.260(12)$ \\
C(4)-N-Mo & $116.83(19)$ & N-C(4)-C(4)\# & $115.47(16)$ \\
\hline
\end{tabular}

${ }^{\mathrm{a}} \mathrm{CNT}$ is the center of gravity of the cyclopentadienyl ring.

Symmetry transformations used to generate equivalent atoms:

\# $\mathrm{x},-\mathrm{y}-1 / 2, \mathrm{z}$ 
Table 4. Apparent rate polymerization rate constants and efficiency factors for the MA polymerizations $\left(30 \%\right.$ v/v in toluene) with $\mathrm{CpMoX}_{2}\left(i \operatorname{Pr}_{2}\right.$-dad $) / \mathrm{YEA}(\mathrm{X}, \mathrm{Y}=\mathrm{Cl}, \mathrm{I})$ at $80^{\circ} \mathrm{C}$.

\begin{tabular}{ccccc}
$\mathrm{X}$ & $\mathrm{Y}$ & $\mathrm{MA} / \mathrm{Mo} / \mathrm{YEA} / \mathrm{Al}$ & $\mathrm{k}_{\mathrm{app}} / \mathrm{min}^{-1}$ & $f$ \\
\hline $\mathrm{Cl}$ & $\mathrm{Cl}$ & $170 / 1 / 1 / 0$ & 0 & - \\
$\mathrm{Cl}$ & $\mathrm{Cl}$ & $168 / 1 / 1 / 1$ & $3.3 \times 10^{-5}$ & 0.37 \\
$\mathrm{Cl}^{\mathrm{a}}$ & $\mathrm{I}$ & $171 / 1 / 1 / 1$ & $3.7 \times 10^{-4}$ & 0.85 \\
$\mathrm{I}$ & $\mathrm{I}$ & $171 / 1 / 1 / 0$ & $5.0 \times 10^{-5}$ & 1.0 \\
$\mathrm{I}$ & $\mathrm{I}$ & $165 / 1 / 1 / 1$ & $1.9 \times 10^{-3}$ & 1.0
\end{tabular}

${ }^{\mathrm{a}}$ From ref. [5]. 
Table of Contents Graphic

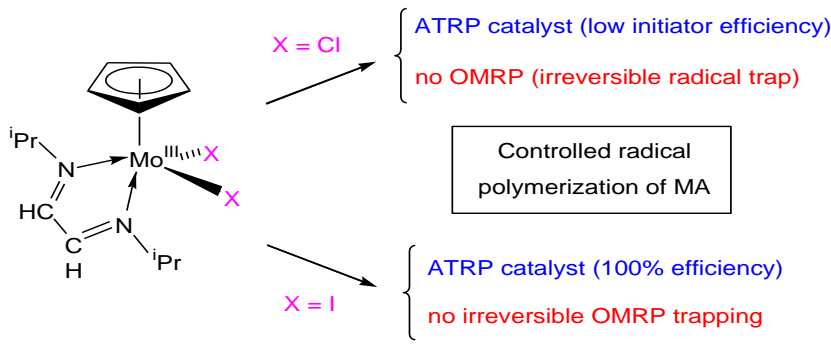

\section{Synopsis}

The interplay of two different mechanisms in controlled radical polymerization, both involving one-electron reactivity on a transition metal complex (one involving halogen atom transfer to a transition metal complex, ATRP; the other one involving the reversible formation of a metal-carbon bond, OMRP) may lead, in certain cases, to the irreversible trapping of the radical growing chains and to a consequent decrease of the "initiator efficiency factor". This contribution highlights this phenomenon for this first time, on the basis of results obtained with a 17-electron half-sandwich Mo ${ }^{\mathrm{III}}$ complex. 